\title{
STRATEGI PENGEMBANGAN AGRIBISNIS STRAWBERY (Fragaria vesca) DI DESA BONTO TALLASA KECAMATAN ULU ERE KABUPATEN BANTAENG
}

\author{
Sahlan Sahlan ${ }^{1}$, Sri Wahyuni ${ }^{2}$ \\ 1.2Fakultas Pertanian, Universitas Muhammadiyah Makassar \\ Jalan.Sultan Alauddin No.259, Makassar, Indonesia \\ E-mail: sahlan@unismuh.ac.id
}

Received: 28 July 2019

Accepted: 17 September 2019

\begin{abstract}
Agricultural development in Bantaeng directed to create an advanced agriculture and resilient, able to increase the yield and quality of production, increase farmers' income and living standards, expanding business opportunities and employment as well as filling and expanding the market. While the use of external inputs - massive and exaggerated to increase the yield and quality of production. The study aims to determine how the Agribusiness Development Strategy Bonto Tallasa Strawbery in Ulu Ere District of Bantaeng. Informants in this study is the unit of analysis (strawberries agribusiness development activities). The informants in this study were obtained intentionally which amounted to 8 people, 4 farmers, 2 Department of Agriculture (Extension) and 2 merchants suspected of knowing about the strawberry agribusiness development in Bonto Tallasa Ulu Ere District of Bantaeng. The results of this study indicate strawberry agribusiness development strategy are: 1 . Improve the quantity to meet market demand. Utilizing existing facilities to develop new technologies. 2. Utilizing the experience of farmers and the potential of nature to improve the quality and quantity of the product in order to gain profit increased or high. 3. To collaborate with the government to obtain quality seeds. 4.Memberikan to improve institutional socialization in the application to overcome pests and diseases. 5. Maintaining quality of fruit to deal with competitiveness. 6. Improving understanding of farmers in processing products to meet safety standards and consumer products industries. 7. Utilizing the experience of farmers to cope with erratic weather changes. 8. Provide training to farmers on cultivation of strawberries products to meet the standards of consumer products and avoid competitiveness. 9. Increase the role of the institution to meet the industry.
\end{abstract}

Keywords : Strategy, Agribusiness Development, Strawberry

\begin{abstract}
ABSTRAK
Pengembangan pertanian di Kabupaten Bantaeng di arahkan untuk menciptakan pertanian yang maju dan tangguh, mampu meningkatkan hasil dan mutu produksi, meningkatkan pendapatan dan taraf hidup petani, memperluas kesempatan berusaha dan menyediakan lapangan kerja serta mengisi dan memperluas pasar. Sementara ini penggunaan input luar secara besar - besaran dan berlebihan untuk meningkatkan hasil dan mutu produksi. Penelitian ini bertujuan untuk mengetahui bagaimana Strategi Pengembangan Agribisnis Strawbery di Desa Bonto Tallasa Kecamatan Ulu Ere Kabupaten Bantaeng. Informan dalam penelitian ini adalah unit analisis (kegiatan pengembangan agribisnis strawbery). Adapun informan dalam penelitian ini yang di peroleh secara sengaja yaitu berjumlah 8 orang, 4 orang petani, 2 Dinas Pertanian (Penyuluh) dan 2 orang pedagang yang diduga mengetahui tentang pengembangan agribisnis strawberry di Desa Bonto Tallasa Kecamatan Ulu Ere Kabupaten Bantaeng. Hasil penelitian ini menunjukkan strategi pengembangan agribisnis strawberry antara lain: 1. Meningkatkan kuantitas untuk memenuhi permintaan pasar. Memanfaatkan sarana yang ada untuk mengembangkan teknologi baru. 2. Memanfaatkan pengalaman petani dan potensi alam untuk meningkatkan kualitas dan kuantitas produk agar mendapatkan laba yang meningkat atau tinggi. 3. Menjalin kerjasama dengan pemerintah untuk memperoleh bibit unggul. 4. Memberikan sosialisasi untuk meningkatkan kelembagaan dalam penerapan untuk menanggulangi hama dan penyakit. 5. Mempertahankan kualitas buah untuk menghadapi daya saing. 6. Meningkatkan pemahaman petani dalam mengolah produk agar mampu memenuhi standar produk konsumen dan industri. 7 . Memanfaatkan pengalaman petani untuk mengatasi perubahan cuaca yang tidak menentu. 8. Memberikan pelatihan kepada petani tentang pengolahan produk strawbery untuk memenuhi standar produk konsumen dan menghindari daya saing. 9. Meningkatkan peran lembaga untuk memenuhi industri.
\end{abstract}

Kata kunci : Strategi, Pengembangan Agribisnis, Strawberry. 


\section{PENDAHULUAN}

Pengembangan pertanian di Kabupaten Bantaeng di arahkan untuk menciptakan pertanian yang maju dan tangguh, mampu meningkatkan hasil dan mutu produksi, meningkatkan pendapatan dan taraf hidup petani, memperluas kesempatan berusaha dan menyediakan lapangan kerja serta mengisi dan memperluas pasar.

Agribisnis Strawbery (Fragaria Vesca) memang berpotensi dikembangkan di Desa Bonto Tallasa mengingat faktor alam yang sesuai untuk pertumbuhan tanaman strawbery dan peluang pasar yang masih terbuka. Meskipun demikian, kedua hal tersebut belum cukup menjamin perkembangan pesat akan terjadi. Berbagai faktor baik internal (seperti kualitas SDM dan keterbatasan modal) maupun eksternal (seperti keterbatasan informasi dan teknologi) sangat mempengaruhi perkembangan agribisnis strawbery tersebut. Kondisi internal maupun eksternal agribisnis strawbery di Desa Bonto tallasa juga harus dipertimbangkan dalam pengambilan straregi pengembangan yang tepat.

Strategi adalah mengembangkan komoditas dan kegiatan agribisnis yang sesuai dengan potensi lahan dan penduduk di suatu wilayah. Salah satunya adalah potensi alam di bidang pertanian. Sampai saat ini pertanian masih menjadi sumber penghidupan bagi sebagian besar masyarakat.

Menurut Saragih (2003), Agribisnis mampu mengakomodasikan tuntutan agar perekonomian nasional terus bertumbuh dan sekaligus memenuhi prinsip kerakyatan, keberlanjutan dan pemerataan baik antar individu maupun antar daerah. Atas dasar pemikiran tersebut maka pembangunan sistem dan usaha agribisnis dipandang sebagai bentuk pendekatan yang paling tepat bagi pembangunan ekonomi Indonesia. Salah satu agribisnis yang memiliki prospek yang cerah adalah agribisnis hortikultura. Menurut Irawan (2003), sejalan dengan pertumbuhan jumlah penduduk, peningkatan pendapatan rumah tangga dan membaiknya kesadaran masyarakat tentang gizi; kebutuhan akan sayur dan buah diperkirakan terus mengalami peningkatan.

Usaha agribisnis memang masih menjanjikan keuntungan. Kunci dari keberhasilan usaha agribisnis adalah pemilihan komoditas yang memiliki nilai ekonomi tinggi. Hal lain yang harus diperhatikan dalam pemilihan komoditas adalah potensi yang dimiliki oleh daerah pengusahaannya. Salah satu komoditas yang bernilai ekonomi tinggi adalah strawbery. Budiman dan Saraswati (2005) mengungkapkan harga jual strawbery yang cukup menjanjikan dan adanya peluang bisnis di dalam dan luar negeri.

\section{Lokasi Penelitian}

\section{BAHAN DAN METODE}

Penelitian ini dilaksanakan Di Kecamatan Ulu Ere Kabupaten Bantaeng, Pemilihan lokasi dilakukan secara sengaja karena daerah tersebut sebagai salah satu penghasil penghasil tanaman strawbery Di Sulawesi Selatan. Penelitian telah berlangsung selama bulan Agustus - September 2018 .

\section{Analisis Data}

Berdasarkan data yang diperoleh baik data primer maupun data skunder yang telah dikumpulkan kemudian dianalisis secara SWOT (Streghts, Weaknesses, Opportunities dan Threats). Analisis SWOT membandingkan antara faktor eksternal Peluang dan Ancaman, dengan faktor internal Kekuatan dan Kelemahan.

\section{Populasi dan Sampel}

Adapun informan dalam penelitian ini adalah unit analisis (kegiatan pengembangan agribisnis strawbery). Adapun informan dalam penelitian ini yang di peroleh secara sengaja yaitu berjumlah 8 orang, 4 orang petani, 2 Dinas Pertanian (Penyuluh) dan 2 orang pedagang yang diduga mengetahui tentang pengembangan agribisnis strawberry di Desa Bonto Tallasa Kecamatan Ulu Ere Kabupaten Bantaeng. Penelitian ini merupakan jenis evaluasi yang menggunakan Faktor internal (Kekuatan dan Kelemahan) dan Faktor eksternal (Peluang dan Ancaman)

\section{Pengumpulan Data}

Adapun metode yang di gunakan dalam penelitian ini adalah :

a) Observasi

Observasi adalah metode pengumpulan data melalui pengamatan langsung atau peninjauan secara cermat dan langsung. Dalam hal ini peneliti dengan berpedoman kepada desain penelitiannya perlu mengunjungi lokasi penelitian untuk mengamati secara langsung berbagai hal atau kondisi yang ada dilapangan. Dalam hal ini penulis menggunakan jenis observasi partisipasi, yaitu observasi yang melibatkan peneliti secara langsung dalam kegiatan 
pengamatan dilapangan serta mengamati kondisi dilapangan yang sebenarnya dalam meningkatkan produktivitas hasil pertanian.

b) Metode wawancara dan Penggunaan Kuisioner

Interview atau wawancara merupakan percakapan yang di arahkan pada masalah tertentu dilakukan secara khusus, bersandar pada keterangan untuk mengatasi kesenjangan pengertian pewawancara dengan yang diwawancarai. Kegiatan ini merupakan proses Tanya jawab secara lisan dari dua orang atau lebih saling berhadapan secara fisik (langsung). Oleh karena itu kualitas hasil wawancara ditentukan oleh pewawancara, responden, pertanyaan dan situasi wawancara.

Metode ini disampaikan kepada tiap - tiap anggota kelompok tani pada lokasi penagambilan sampel dalam upaya untuk memperoleh data - data tentang Strategi Pengembangan Agribisnis Strawbery.

c) Dokumentasi

Dokumentasi adalah mengumpulkan data dengan cara mengalir atau mengambil data-data dari catatan, dokumentasi, administrasi yang sesuai dengan masalah yang diteliti. Dalam hal ini dokumentasi atau arsip - arsip dari lembaga yang di teliti.

\section{Analisis Data}

Analisis SWOT membandingkan antara faktor eksternal Peluang dan Ancaman, dengan faktor internal Kekuatan dan Kelemahan.

Adapun pengertian strengths, Weaknesses, Opportunities, dan Thereats sebagai berikut :

a. Strength (Kekuatan)

Strength merupakan kondisi kekuatan yang terdapat dalam organisasi, proyek, atau konsep bisnis yang ada. Kekuatan yang dianalisis merupakan faktor yang terdapat dalam tubuh organisasi, proyek, atau konsep bisnis itu sendiri.

b. Weakness (Kelemahan)

Weakness merupakan kondisi kelemahan yang terdapat dalam organisasi, proyek, atau konsep bisnis yang ada. Kelemahan yang dianalisis merupakan faktor yang terdapat dalam tubuh organisasi, proyek, atau konsep bisnis itu sendiri.

c. Opportunities (Peluang)

Opportunities merupakan kondisi peluang berkembang di masa datang yang akan terjadi. Kondisi yang terjadi merupakan peluang dari organisasi, proyek, atau konsep bisnis itu sendiri misalnya, kebijakan pemerintah, dan kondisi lingkungan sekitar.

b. Threat (Ancaman)

Threat merupakan kondisi yang mengancam dari luar. Ancaman ini dapat mengganggu organisasi, proyek, atau konsep bisnis itu sendiri.

Prospek pengembangan suatu perusahaan dalam mengolah sebuah produk dapat dianalisis dengan penetapan faktor-faktor yang menjadi kekuatan, kelemahan, peluang, dan ancaman dengan menggunakan analis SWOT (Strength, Weaknesses, Opportunities dan Threat).

Untuk mendapatkan nilai bobot (Yantu,2012) di gunakan dengan rumus :

$$
B \mathrm{i}=\frac{\mathrm{Ri}}{\sum \mathrm{Ri}}
$$

Keterangan :

Bi : Bobot faktor

$\mathrm{Ri} \quad$ : Rating

$\sum \mathrm{Ri} \quad$ : Total rating atau jumlah rating

Dianalisis dengan matriks IFAS (Internal

Factors Analysis Summary) dan EFAS

(Eksternal Factors Analysis Summary).

Tabel 1. Matriks SWOT

\begin{tabular}{|c|c|c|}
\hline EFAS & $\begin{array}{l}\text { Strengths }(\mathrm{S}) \\
\quad \text { Tentukan } \\
5-10 \\
\text { faktor } \\
\quad \text { kekuatan } \\
\quad \text { internal }\end{array}$ & $\begin{array}{l}\text { Weaknesses }(\mathrm{W}) \\
>\text { Tentukan 5- } \\
10 \text { faktor } \\
\text { kelemahan } \\
\text { internal }\end{array}$ \\
\hline 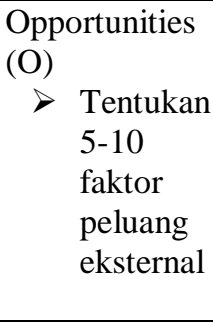 & $\begin{array}{l}\text { Strategi SO } \\
\text { Ciptakan } \\
\text { strategi yang } \\
\text { menggunakan } \\
\text { kekuatan untuk } \\
\text { memanfaatkan } \\
\text { peluang yang } \\
\text { ada. } \\
\end{array}$ & $\begin{array}{l}\text { Strategi WO } \\
\text { Ciptakan strategi } \\
\text { yang } \\
\text { meminimalkan } \\
\text { kelemahan } \\
\text { untuk } \\
\text { memanfaatkan } \\
\text { peluang. }\end{array}$ \\
\hline \begin{tabular}{l} 
Threaths $(\mathrm{T})$ \\
\multicolumn{1}{c}{ Tentukan } \\
$5-10$ \\
faktor \\
ancaman \\
eksternal
\end{tabular} & $\begin{array}{l}\text { Strategi ST } \\
\text { Ciptakan } \\
\text { strategi yang } \\
\text { menggunakan } \\
\text { kekuatan untuk } \\
\text { mengatasi } \\
\text { ancaman }\end{array}$ & $\begin{array}{l}\text { Strategi WT } \\
\text { Ciptakan strategi } \\
\text { untuk } \\
\text { meminimalkan } \\
\text { kelemahan dan } \\
\text { menghindari } \\
\text { ancaman. }\end{array}$ \\
\hline
\end{tabular}

1. Strategi SO

Strategi ini dibuat berdasarkan jalan pikiran perusahaan, yaitu dengan memanfaatkan seluruh kekuatan untuk merebut dan memanfaatkan peluang sebesar - besarnya.

2. Strategi ST

Ini adalah strategi dalam menggunakan kekuatan yang dimiliki perusahaan untuk mengatasi ancaman. 
3. Strategi WO

Strategi ini diterapkan berdasarkan pemanfaatan peluang yang ada dengan cara meminimalkan kelemahan yang ada.

4. Strategi WT

Strategi ini didasarkan pada kegiatan yang bersifat defensive dan berusaha meminimalkan kelemahan yang ada serta menghindari ancaman.

\section{HASIL DAN PEMBAHASAN}

Hasil klarifikasi faktor strategi internal (kekuatan dan kelemahan) bagi strategi pengembangan agribisnis strawbery di Desa Bonto Tallasa, Kecamatan Ulu Ere, Kabupaten Bantaeng dapat dilihat pada Tabel 2.

Tabel 2. IFAS (Internal Factor Analysis Summary).

Sumber : Data Primer Setelah Diolah,2018

Pada Tabel 2 faktor internal menunjukkan terdapat 5 kekuatan dan 5 kelemahan yang ada bagi strategi pengembangan agribisnis strawbery di Desa Bonto Tallasa Kecamatan Ulu Ere Kabupaten Bantaeng. Faktor kekuatan dan kelemahan ini disusun berdasarkan bobot dampak sangat penting hingga tidak penting. Kekuatan dan kelemahan yang diberikan terhadap strategi pengembangan agribisnis strawbery. Data menunjukkan bahwa bobot kekuatan lebih besar dibandingkan dengan bobot kelemahan. Tergambar jelas bahwa pada lokasi penelitian memiliki kekuatan yang lebih besar dibandingkan dengan kelemahan.

Kekuatan diberikan dengan rating pada skala terbesar 4 hingga skala terkecil 1dan setiap kekuatan diberikan rating 1 hingga 4 didasarakan pada hasil wawancara dengan petani sebagai pelaku. Hasil perkalian antara bobot dengan rating merupakan skor bagi faktor kekuatan dan kelemahan strategi pengembangan agribisnis strawbery. Total nilai skor kekuatan dan kelemahan adalah 2,84.

\section{a. Kekuatan}

1. Kemauan petani untuk mengembangkan komoditas strawbery. Oleh karena itu, dalam hasil klarifikasi diberikan rating 4. Menurut petani di Desa Bonto Tallasa Kecamatan Ulu Ere Kabupaten Bantaeng buahnya sedang sedang, rasa tidak terlalu masam, daya tahan juga cukup baik.

2. Ketersediaan sarana produksi yang mudah diakses oleh para petani. Berdasarkan hasil klarifikasi diberikan rating 4. Masyarakat setempat sangat tertarik untuk membudidayakan strawbery. Respon positif terhadap perkenalan strawbery menjadi kekuatan untuk pengembangan agribisnis strawbery.

3. Pemahaman atau pengalaman budidaya yang tinggi. Hasil klarifikasi diberikan rating 3. Para petani sangat memerlukan kemudahan akses terhadap berbagai sarana produksi. Kemudahan akses terhadap sarana produksi akan mempermudah pelaksanaan budidaya strawbery. Sebaliknya bila sarana produksi sulit didapat maka petanipun akan kesulitan menjalankan proses budidaya.

4. Struktur tanah yang mendukung. Berdasarkan hasil klarifikasi diberikan rating 2, dengan melakukan wawancara dan observasi di Desa Bonto Tallasa Kecamatan Ulu Ere Kabupaten Bantaeng.

5. Kualitas buah yang baik, berdasarkan hasil

\begin{tabular}{|c|c|c|c|c|}
\hline \multirow{2}{*}{ No } & \multicolumn{4}{|c|}{ Matriks Faktor Internal } \\
\hline & Kekuatan & Bobot & Rating & Nilai \\
\hline 1. & $\begin{array}{l}\text { Respon } \\
\text { masyarakat } \\
\text { setempat yang } \\
\text { positif terhadap } \\
\text { komoditas } \\
\text { strawbery. } \\
\end{array}$ & 0,16 & 4 & 0,64 \\
\hline 2. & \begin{tabular}{lr}
\multicolumn{2}{l}{ Ketersediaan } \\
sarana produksi \\
yang $\quad$ mudah \\
diakses & oleh para \\
petani & \\
\end{tabular} & 0,16 & 4 & 0,64 \\
\hline 3. & $\begin{array}{ll}\text { Pemahaman } & \text { atau } \\
\text { pengalaman } & \\
\text { budidaya } & \text { yang } \\
\text { tinggi } & \\
\end{array}$ & 0,12 & 3 & 0,36 \\
\hline 4. & $\begin{array}{l}\text { Struktur tanah } \\
\text { yang mendukung }\end{array}$ & 0,08 & 2 & 0,16 \\
\hline 5. & $\begin{array}{l}\text { Kualitas buah } \\
\text { yang baik }\end{array}$ & 0.08 & 2 & 0,16 \\
\hline No & Kelemahan & & & \\
\hline 1. & $\begin{array}{ll}\text { Penggunaan } & \text { bibit } \\
\text { yang } & \text { turun } \\
\text { temurun } & \\
\end{array}$ & 0.04 & 1 & 0,04 \\
\hline 2. & $\begin{array}{l}\text { Permodalan yang } \\
\text { masih lemah }\end{array}$ & 0,08 & 2 & 0,16 \\
\hline 3. & $\begin{array}{l}\text { Kelembagaan } \\
\text { yang kurang } \\
\text { menyentuh petani }\end{array}$ & 0,08 & 2 & 0,16 \\
\hline 4. & $\begin{array}{l}\text { Kuantitas dan } \\
\text { kualitas produk } \\
\text { olahan yang masih } \\
\text { rendah }\end{array}$ & 0,12 & 2 & 0,16 \\
\hline 5. & $\begin{array}{l}\text { Serangan hama } \\
\text { dan penyakit }\end{array}$ & 0,12 & 3 & 0,36 \\
\hline & Total & 1.00 & 25 & 2,84 \\
\hline
\end{tabular}

klarifikasi diberikan rating 2 . Ini merupakan 
kekuatan bagi pengembangan agribisnis strawbery.

\section{b. Kelemahan}

1. Penggunaan bibit yang turun temurun, berdasarkan hasil klarifikasi diberi rating 1 . Bibit adalah bibit, ini artinya petani menggunakan bibit yang terus diturunkan.

2. Permodalan yang masih lemah. Berdasarkan hasil klarifikasi di berikan rating 2. Kondisi masyarakat pedesaan pada umumnya hidup dalam kesedarhanaan dan keterbatasan, termasuk di dalamnya keterbatasan modal. Kebanyakan hanya mengandalkan hasil pertanian yang hanya cukup untuk kebutuhan sehari-hari.

3. Kelembagaan yang kurang menyentuh seluruh petani, berdasarkan hasil klarifikasi diberikan rating 2 . Keberadaan organisasi sesungguhnya sangat diperlukan terutama sebagai media komunikasi antar petani maupun antara petani dan pihak luar.

4. Kuantitas dan kualitas produk olahan yang masih rendah, berdasarkan hasil klarifikasi diberikan rating 2. Berdasarkan hasil wawancara dan observasi, keinginan sebagian masyarakat dan dorongan pemerintah pada untuk dapat menghasilkan produk-produk olahan strawbery.

5. Serangan hama dan penyakit, berdasarkan hasil klarifikasi diberikan rating 3 . Berdasarkan hasil wawancara dan observasi.

Sedangkan hasil klarifikasi faktor eksternal (peluang dan ancaman) dapat dilihat pada Tabel 3 berikut:

Tabel 3 EFAS (External Factor Analysis Summary)

\begin{tabular}{|c|c|c|c|c|}
\hline \multirow[b]{2}{*}{ No } & \multicolumn{4}{|c|}{ Matriks Faktor Eksternal } \\
\hline & Peluang & Bobot & $\begin{array}{c}\text { Ratin } \\
\text { g }\end{array}$ & Nilai \\
\hline 1. & $\begin{array}{l}\text { Tingginya } \\
\text { permintaan pasar }\end{array}$ & 0,12 & 3 & 0,36 \\
\hline 2. & $\begin{array}{l}\text { Perkembangan } \\
\text { teknologi }\end{array}$ & 0,16 & 4 & 0,64 \\
\hline 3. & $\begin{array}{l}\text { Potensi alam yang } \\
\text { sangat sesuai } \\
\text { untuk budidaya } \\
\text { strawbery. }\end{array}$ & 0,08 & 2 & 0,16 \\
\hline 4. & $\begin{array}{l}\text { Adanya partisipasi } \\
\text { petani. }\end{array}$ & 0,08 & 2 & 0,16 \\
\hline 5. & $\begin{array}{l}\text { Dengan adanya } \\
\text { dukungan } \\
\text { pemerintah. }\end{array}$ & 0,08 & 2 & 0,16 \\
\hline No & Ancaman & & & \\
\hline 1 & $\begin{array}{lr}\text { Masuknya } & \text { produk } \\
\text { strawbery } & \text { dari } \\
\text { daerah lain } & \end{array}$ & 0,08 & 2 & 0,16 \\
\hline
\end{tabular}

\begin{tabular}{|c|l|c|c|c|}
\hline 2 & $\begin{array}{l}\text { Belum ada industri } \\
\text { yang mau menjadi } \\
\text { mitra }\end{array}$ & 0,08 & 2 & 0,16 \\
\hline 3 & $\begin{array}{l}\text { Standar produk } \\
\text { konsumen }\end{array}$ & 0,08 & 2 & 0,16 \\
\hline 4 & $\begin{array}{l}\text { Perubahan cuaca } \\
\text { yang tak menentu }\end{array}$ & 0,12 & 3 & 0,36 \\
\hline 5 & $\begin{array}{l}\text { Mempunyai daya } \\
\text { saing }\end{array}$ & 0,12 & 3 & 0,36 \\
\hline \multicolumn{2}{|c|}{ Total } & 1,00 & 25 & 2,68 \\
\hline
\end{tabular}

Sumber ; Data Primer Setelah diolah, 2018.

Tabel 3 menunjukkan terdapat 5 peluang dan 5 ancaman yang dihadapi oleh desa ini dalam strategi pengembangan strawbery. Ini disusun dengan bobot sangat penting hingga tidak penting dari dampak ancaman dan peluang yang ada pada strategi pengembangan agribisnis strawbery. Bobot nilai peluang lebih besar daripada bobot nilai ancaman. Ini menunjukkan bahwa pada desa ini memiliki peluang yang lebih besar dibandingkan dengan ancaman yang akan dihadapi.

Peluang diberikan rating dengan skala 4 hingga skala terkecil 1 dan setiap ancaman diberikan rating dengan skala 1 hingga 4 didasarkan pada hasil wawancara dengan petani serta kondisi lokasi penelitian. Hasil perkalian antara bobot dengan rating merupakan skor bagi setiap peluang dan ancaman. Total nilai skor peluang dan ancaman 2,68. Nilai skor ini diperlukan untuk matriks eksternal internal posisi desa ini dalam pengembangan agribisnis strawbery.

\section{a. Peluang}

1. Tingginya permintaan pasar di Desa Bonto Tallasa Kecamatan Ulu Ere Kabupaten Bantaeng jumlahnya jauh lebih sedikit. Berdasarkan hasil klarifikasi diberikan rating 3. Bagi penduduk di Desa Bonto Tallasa Kecamatan Ulu Ere Kabupaten Bantaeng harga strawbery yang mencapai Rp. 40.000,00 per kilogram tidak memberatkan bagi para konsumen.

2. Perkembangan teknologi dewasa ini mengalami kemajuan yang sangat pesat di berbagai bidang. Berdasarkan hasil klarifikasi diberikan rating 4. Kondisi ini menjadi peluang yang dapat dimanfaatkan untuk mendorong perkembangan agribisnis strawbery di Bonto Tallasa Kecamatan Ulu Ere Kabupaten Bantang. Teknologi yang diterapkan dalam budidaya di Desa Bonto Tallasa Kecamatan Ulu Ere Kabupaten Bantaeng masih tergolong sederhana. 
3. Potensi alam yang sangat sesuai untuk budidaya strawbery. Berdasarkan hasil klarifikasi diberikan rating 2. Kondisi alam yang sangat sesuai untuk pengembangan agribisnis strawbery. Curah hujan yang relatif tinggi dan kelembaban yang tinggi merupakan kondisi ideal bagi pertumbuhan strawbery.

4. Adanya partisipasi petani. Berdasarkan hasil klarifikasi diberikan rating 2 . Berdasarkan hasil wawancara dengan petani.

5. Dengan adanya dukungan pemerintah. Berdasarkan hasil klarifikasi di berikan rating 2.

\section{b. Ancaman}

1. Masuknya produk strawbery dari daerah lain, berdasarkan hasil klarifikasi diberikan rating 2. Pesaing yang ada bagi agribisnis strawbery di Desa Bonto Tallasa adalah masuknya buah strawbery yang dipasok dari Desa Loka. Ini merupakan ancaman bagi pengembangan bagi agribisnis strawbery.

2. Belum ada industri yang mau menjadi mitra, berdasrkan hasil klarifikasi diberikan rating 2 . Belum adanya mitra yang mau menampung berapapun hasil panen dapat menjadi ancaman produk melimpah.

3. Standar produk konsumen, berdasarkan hasil klarifikasi diberikan rating 3. Ini merupakan ancaman bagi pengembangan agribisnis strawbery di Desa Bonto Tallasa Kecamatan Ulu Ere Kabupaten Bantaeng.

4. Perubahan cuaca tidak menentu, berdasarkan hasil klarifikasi diberikan rating 3. Hujan yang tidak menentu dan kemarau yang berkepanjangan menyebabkan tanaman susah beradaptasi dengan lingkungan yang ada.

5. Mempunyai daya saing, berdasarkan hasil klarifikasi di berikan rating 3 . Berdasarkan hasil wawancara dan observasi di Desa Bonto Tallasa Kecamatan Ulu Ere kabupaten Bantaeng.

Nilai EFAS dan IFAS perusahaan pada matriks eksternal - internal dapat diketahui pada gambar matriks $5(2,84-2,68)$.

Matriks eksternal - internal posisi pengembangan agribisnis strawberry (EFAS-IFAS)

\begin{tabular}{|c|c|c|c|c|}
\hline \multirow{2}{*}{$\begin{array}{c}\text { Total } \\
\text { skor } \\
\text { fakto } \\
\mathbf{r} \\
\text { ekster } \\
\text { nal }\end{array}$} & & $\begin{array}{l}\text { Tinggi } \\
(4-3)\end{array}$ & Rata-rata(3-2) & $\mid \begin{array}{c}\text { Lema } \\
\mathrm{h}(2- \\
1)\end{array}$ \\
\hline & $\begin{array}{l}\text { Ting } \\
\text { gi } \\
(4-3) \\
\end{array}$ & $\begin{array}{c}1 \\
\text { Pertumb } \\
\text { uhan }\end{array}$ & $\begin{array}{c}2 \\
\text { Pertumbuhan }\end{array}$ & $\begin{array}{c}3 \\
\text { Penci } \\
\text { utan }\end{array}$ \\
\hline \multirow[t]{2}{*}{2,68} & $\begin{array}{c}\text { Seda } \\
\text { ng } \\
(3-2)\end{array}$ & $\begin{array}{c}4 \\
\text { Stabilita } \\
\mathrm{S}\end{array}$ & $\begin{array}{c}5 \\
\begin{array}{c}\text { Pertumbuhan/s } \\
\text { tabilitas }\end{array}\end{array}$ & $\begin{array}{c}6 \\
\text { Penci } \\
\text { utan }\end{array}$ \\
\hline & $\begin{array}{l}\text { Ren } \\
\text { dah } \\
(2-1)\end{array}$ & $\begin{array}{c}7 \\
\text { Pertumb } \\
\text { uhan }\end{array}$ & $\begin{array}{c}8 \\
\text { Pertumbuhan }\end{array}$ & $\begin{array}{c}9 \\
\text { Likui } \\
\text { dasi }\end{array}$ \\
\hline
\end{tabular}

Sumber ; Data Primer Setelah diolah, 2018.

Posisi matriks strategi yang berbeda sebagai berikut :

Posisi 1 : Strategi konsentrasi melalui intergrasi vertikal.

Posisi 2: Strategi konsentrasi melalui intergrasi horizontal.

Posisi 3 : Strategi turnaround.

Posisi 4 : Strategi stabilitas.

Posisi 5 : Strategi konsentrasi melalui integrasi horizontal/stabilitas.

Posisi 6 : Strategi divestasi.

Posisi 7 : Strategi diversifikasi konsentrik.

Posisi 8 : Strategi diversifikasi konglomerat.

Posisi 9 : Strategi likuidasi atau bangkrut.

Strategi pengembangan agribisnis strawbery di Desa Bonto Tallasa Kecamatan Ulu Ere Kabupaten Bantaeng setelah dianalisis berada pada posisi matriks 5 , menunjukkan bahwa desa ini dalam membudidayakan tanaman strawbery mengalami perkembangan baik. Strategi yang diberlakukan adalah strategi pertumbuhan (growth strategy). Dimana desa ini didesain untuk mencapai pertumbuhan baik dalam pengembangan strawbery. Berdasarkan matriks EFAS-IFAS dapat dijadikan landasan dalam penyusunan alternative bagi Desa Bonto Tallasa, Kecamatan Ulu Ere, Kabupaten Bantaeng guna menerapkan strategi pengembangan agribisnis strawbery. Penyusunan alternatif - alternatif didasarkan pada unsur unsur kekuatan (Strengths), kelemahan (Weakness), peluang (Opportunities), dan ancaman (Threats). 
Matriks ringkasan analisis SWOT yang berisikan keadaan internal dan eksternal perusahaan dapat dilihat pada Tabel 4 .

Tabel 4 . Analisis SWOT

\begin{tabular}{|c|c|c|}
\hline Eksternal & $\begin{array}{l}\text { Kekuatan } \\
\text { (Strength) } \\
\text { 1. Respon } \\
\text { masyarakat } \\
\text { setempat } \\
\text { yang positif } \\
\text { terhadap } \\
\text { komoditas } \\
\text { strawbery. } \\
\text { 2. Ketersediaan } \\
\text { sarana } \\
\text { produksi yang } \\
\text { mudah } \\
\text { diakses oleh } \\
\text { para petani. } \\
\text { 3. Pemahaman } \\
\text { atau } \\
\text { pengalaman } \\
\text { budidaya } \\
\text { yang tinggi } \\
\text { 4. Struktur tanah } \\
\text { yang } \\
\text { mendukung } \\
\text { 5. Kualitas buah } \\
\text { yang baik }\end{array}$ & $\begin{array}{l}\text { Kelemahan } \\
\text { (Weakness) } \\
\text { 1. Penggunaan } \\
\text { bibit hibrida } \\
\text { yang turun } \\
\text { menurun. } \\
\text { 2. Permodalan } \\
\text { yang masih } \\
\text { lemah. } \\
\text { 3. Kelembagaa } \\
\text { n yang } \\
\text { kurang } \\
\text { menyentuh } \\
\text { petani. } \\
\text { 4. Kuantitas } \\
\text { dan kualitas } \\
\text { produk } \\
\text { olahan yang } \\
\text { masih } \\
\text { rendah. } \\
\text { 5. Hama dan } \\
\text { penyakit }\end{array}$ \\
\hline $\begin{array}{l}\text { Peluang } \\
\text { (Oppurtunit } \\
\text { ies) } \\
\text { 1. Pasar } \\
\text { yang } \\
\text { masih } \\
\text { terbuka. } \\
\text { 2. Perkemb } \\
\text { angan } \\
\text { teknologi } \\
\text {. } \\
\text { 3. Potensi } \\
\text { alam } \\
\text { yang } \\
\text { sangat } \\
\text { sesuai } \\
\text { untuk } \\
\text { budidaya } \\
\text { strawbery } \\
\text {. } \\
\text { 4. Adanya } \\
\text { partisifasi } \\
\text { petani } \\
\text { 5ukunga } \\
\mathrm{n} \\
\text { pemerint } \\
\text { ah }\end{array}$ & \begin{tabular}{|l} 
SO \\
1. Meningkatkan \\
kuantitas \\
untuk \\
memenuhi \\
permintaan \\
pasar.(S1,O1) \\
2. Memanfaatka \\
n sarana yang \\
ada untuk \\
mengembangk \\
an teknologi \\
baru(S3,O2, \\
O5). \\
3emanfaatka \\
n pengalaman \\
petani dan \\
potensi alam \\
untuk \\
meningkatkan \\
kualitas dan \\
kuantitas \\
produk agar \\
mendapatkan \\
laba yang \\
meningkat \\
atau tinggi. \\
(S2,S4, S5, \\
O3,O4)
\end{tabular} & $\begin{array}{l}\text { WO } \\
\text { 1. Menjalin } \\
\text { kerjasama } \\
\text { dengan } \\
\text { pemerintah } \\
\text { untuk } \\
\text { memperoleh } \\
\text { bibit } \\
\text { unggul.(W1, } \\
\text { O5) } \\
\text { 2. Memberikan } \\
\text { sosialisasi } \\
\text { untuk } \\
\text { meningkatka } \\
\mathrm{n} \\
\text { kelembagaan } \\
\text { dalam } \\
\text { penerapan } \\
\text { untuk } \\
\text { menanggulan } \\
\text { gi hama dan } \\
\text { penyakit.(W } \\
\text { 3,O5,W5) }\end{array}$ \\
\hline
\end{tabular}

\begin{tabular}{|c|c|c|}
\hline $\begin{array}{l}\text { Ancaman } \\
\text { (Threats) } \\
\text { 1. Masukny } \\
\text { a produk } \\
\text { strawbery } \\
\text { dari } \\
\text { daerah } \\
\text { lain. } \\
\text { 2. Belum } \\
\text { ada } \\
\text { industri } \\
\text { yang mau } \\
\text { menjadi } \\
\text { mitra. } \\
\text { 3. Standar } \\
\text { produk } \\
\text { konsume } \\
\text { n. } \\
\text { 4. Perubaha } \\
\text { n cuaca } \\
\text { yang tak } \\
\text { menentu. } \\
\text { 5. Mempun } \\
\text { yai daya } \\
\text { saing }\end{array}$ & $\begin{array}{l}\text { ST } \\
\text { 1. Mempertahan } \\
\text { kan kualitas } \\
\text { buah untuk } \\
\text { menghadapi } \\
\text { daya } \\
\text { saing.(S1, T5) } \\
\text { 2. Meningkatkan } \\
\text { pemahaman } \\
\text { petani dalam } \\
\text { mengolah } \\
\text { produk agar } \\
\text { mampu } \\
\text { memenuhi } \\
\text { standar produk } \\
\text { konsumen dan } \\
\text { industri.(S4,T } \\
\text { 3, T2,S2) } \\
\text { Memanfaatka } \\
\mathrm{n} \text { pengalaman } \\
\text { petani untuk } \\
\text { mengatasi } \\
\text { perubahan } \\
\text { cuaca yang } \\
\text { tidak } \\
\text { menentu.(S4, } \\
\text { T4) }\end{array}$ & $\begin{array}{l}\text { WT } \\
\text { 1. Memberikan } \\
\text { pelatihan } \\
\text { kepada } \\
\text { petani } \\
\text { tentang } \\
\text { pengolahan } \\
\text { produk } \\
\text { strawbery } \\
\text { untuk } \\
\text { memenuhi } \\
\text { standar } \\
\text { produk } \\
\text { konsumen } \\
\text { dan } \\
\text { menghindari } \\
\text { daya } \\
\text { saing.(W2,W } \\
\text { 4,T1,T3,T5) } \\
\text { Meningkatka } \\
\text { n peran } \\
\text { lembaga } \\
\text { untuk } \\
\text { memenuhi } \\
\text { industri.(W3, } \\
\text { T2) }\end{array}$ \\
\hline
\end{tabular}

Sumber; Data Primer Setelah diolah, 2018.

Ada empat gabungan kekuatan dan peluang (SO), kekuatan dan ancaman (ST), kelemahan dan peluang (WO) serta kelemahan dan ancaman (WT). Hal ini dapat menjadi landasan bagi Desa Bonto Tallasa, Kecamatan Ulu Ere Kabupaten Bantaeng dalam pengembangan agribisnis strawbery. Adapun uraian dari gabungan analisis SWOT tersebut adalah :

\section{a.Strategi SO}

1. Meningkatkan kuantitas untuk memenuhi permintaan pasar.

2. Memanfaatkan sarana yang ada untuk mengembangkan teknologi baru

3. Memanfaatkan pengalaman petani dan potensi alam untuk meningkatkan kualitas dan kuantitas produk agar mendapatkan laba yang meningkat atau tinggi.

b.Strategi WO

1. Menjalin kerjasama dengan pemerintah untuk memperoleh bibit unggul.

2. Memberikan sosialisasi untuk meningkatkan kelembagaan dalam penerapan untuk menanggulangi hama dan penyakit

\section{c.Strategi ST}

1. Mempertahankan kualitas buah untuk menghadapi daya saing.

2. Meningkatkan pemahaman petani dalam mengolah produk agar mampu memenuhi standar produk konsumen dan industri. 
3. Memanfaatkan pengalaman petani untuk mengatasi perubahan cuaca yang tidak menentu.

d.Strategi WT

1. Memberikan pelatihan kepada petani tentang pengolahan produk strawbery untuk memenuhi standar produk konsumen dan menghindari daya saing.

2. Meningkatkan peran lembaga untuk memenuhi industri.

\section{KESIMPULAN}

Berdasarkan Hasil penelitian tentang Strategi Prengembangan Agribisnis Strawbery di Desa Bonto Tallasa Kecamatan Ulu Ere Kabupaten Bantaeng maka dapat disimpulkan sebagai berikut :

1. Meningkatkan kuantitas untuk memenuhi permintaan pasar.

2. Memanfaatkan sarana yang ada untuk mengembangkan teknologi baru.

3. Memanfaatkan pengalaman petani dan potensi alam untuk meningkatkan kualitas dan kuantitas produk agar mendapatkan laba yang meningkat atau tinggi.

4. Menjalin kerjasama dengan pemerintah untuk memperoleh bibit unggul.

5. Memberikan sosialisasi untuk meningkatkan kelembagaan dalam penerapan untuk menanggulangi hama dan penyakit.

6. Mempertahankan kualitas buah untuk menghadapi daya saing.

7. Meningkatkan pemahaman petani dalam mengolah produk agar mampu memenuhi standar produk konsumen dan industri.

8. Memanfaatkan pengalaman petani untuk mengatasi perubahan cuaca yang tidak menentu.

9. Memberikan pelatihan kepada petani tentang pengolahan produk strawbery untuk memenuhi standar produk konsumen dan menghindari daya saing.

10. Meningkatkan peran lembaga untuk memenuhi industri.

\section{UCAPAN TERIMA KASIH}

Pada kesempatan ini penulis mengucapkan terima kasih kepada Rektor Universitas Muhammadiyah Makassar yang telah bersedia memberikan bantuan pendanaan yang mendukung penelitian ini, dan Dekan Fakultas Pertanian Universitas Muhammadiyah Makassar selaku pimpinan Fakultas yang telah memberikan Dukungan dan memberikan bimbingan serta pengarahan dalam penelitian. Penulis juga menyampaikan terima kasih kepada Seluruh keluarga terutama kepada kedua orang tua dan istri yang tercinta atas segala do'a dan dorongan semangat yang selalu diberikan serta Seluruh Dosen dan Civitas Akademik Fakultas Pertanian Universitas Muhammadiyah Makassar dan sahabat- sahabat yang telah memberikan bantuan dan perhatian selama penelitian.

\section{DAFTAR PUSTAKA}

Arifin, Bustanul. 2004. Analisis Ekonomi Pertanian Indonesia. Kompas Media Nusantara. Jakarta.

Budiman, S dan Saraswati, D. 2006. Berkebun Stroberi Secara Komersil. Penebar Swadaya. Jakarta.

Bungaran Saragih, 2001. Suara dari Bogor: Membangun Sistem Agribisnis Yayasan USESE, Bogor.

Hunger, J. dan Wheelen, T. 2003. Manajemen Strategis. PT Gramedia Pustaka Utama. Jakarta

Jauch and Glueck. 1997. Manajemen Strategis dan Kebijaksanaan Perusahaan. Edisi II. Erlangga. Jakarta

Rangkuti, F. 2001. Analisis SWOT Teknik Membedah Kasus Bisnis. Gramedia Pustaka Utama. Jakarta.

Said, E. Gumbira dan Intan, A. Harizt. 2004. Manajemen Agribisnis. Ghalia Indonesia, Jakarta.

Saragih, Bungaran. 2001. Pembangunan Sistem Agrobisnis di Indonesia dan Peran Public Relation. Jurnal Sosial Ekonomi Pertanian dan Agrobisnis.

Sugiarto, dkk.,Teknik Sampling (Jakarta: Gramedia Pustaka Utama, 2001), pp. 299.

Yantu, M.R. 2012 Makroekonometrik Wilayah Sulawesi Tengah Berbasis Agribisnis. Makalah Kuliah Umum Program Paskasarjana Universitas Tadulako, 2012. Ruang Nuri Pascasarjana UNTAD Kampus Bumi Sagu Setia Budi Palu. 